OPEN ACCESS

Edited by:

Sayyed Mohsen Fatemi,

Harvard University, USA

Reviewed by:

Valentina Tesio,

University of Turin, Italy

Michelle Dow Keawphalouk,

Harvard and MIT, USA

*Correspondence:

Slawomir Wojniusz

swavekwoj@gmail.com

${ }^{\dagger}$ Joint first authorship.

Specialty section:

This article was submitted to

Psychology for Clinical Settings,

a section of the journa

Frontiers in Psychology

Received: 02 November 2015

Accepted: 27 June 2016

Published: 12 July 2016

Citation:

Wojniusz S, Callens N, Sütterlin S, Andersson S, De Schepper J, Gies I, Vanbesien J, De Waele K, Van Aken S,

Craen $M$, Vögele C, Cools $M$ and Haraldsen IR (2016) Cognitive,

Emotional, and Psychosocial

Functioning of Girls Treated with Pharmacological Puberty Blockage for Idiopathic Central Precocious Puberty.

Front. Psychol. 7:1053

doi: 10.3389/fpsyg.2016.01053

\section{Cognitive, Emotional, and Psychosocial Functioning of Girls Treated with Pharmacological Puberty Blockage for Idiopathic Central Precocious Puberty}

\author{
Slawomir Wojniusz ${ }^{1,2 * t}$, Nina Callens ${ }^{3 \dagger}$, Stefan Sütterlin ${ }^{1,4}$, Stein Andersson ${ }^{1,5}$, \\ Jean De Schepper ${ }^{3,6}$, Inge Gies ${ }^{6}$, Jesse Vanbesien ${ }^{6}$, Kathleen De Waele $^{3}$, Sara Van Aken ${ }^{3}$, \\ Margarita Craen ${ }^{3}$, Claus Vögele ${ }^{7}$, Martine Cools ${ }^{3}$ and Ira R. Haraldsen ${ }^{1}$ \\ 1 Division of Surgery and Clinical Neuroscience, Department of Medical Neurobiology, Oslo University Hospital, Oslo, Norway, \\ ${ }^{2}$ Department of Physiotherapy, Oslo and Akershus University College of Applied Sciences, Oslo, Norway, ${ }^{3}$ Division of \\ Pediatric Endocrinology, Department of Pediatrics, Ghent University Hospital and Ghent University, Ghent, Belgium, ${ }^{4}$ Section \\ for Psychology, Lillehammer University College, Lillehammer, Norway, ${ }^{5}$ Department of Psychology, University of Oslo, Oslo, \\ Norway, ${ }^{6}$ Division of Pediatric Endocrinology, Department of Pediatrics, Brussels University Hospital, Brussels, Belgium, \\ ${ }^{7}$ Research Unit INSIDE, Institute for Health and Behavior, University of Luxembourg, Luxembourg, Luxembourg
}

Central precocious puberty (CPP) develops due to premature activation of the hypothalamic-pituitary-gonadal (HPG) axis, resulting in early pubertal changes and rapid bone maturation. CPP is associated with lower adult height and increased risk for development of psychological problems. Standard treatment of CPP is based on postponement of pubertal development by blockade of the HPG axis with gonadotropin releasing hormone analogs ( $\mathrm{GnRHa}$ ) leading to abolition of gonadal sex hormones synthesis. Whereas the hormonal and auxological effects of $\mathrm{GnRHa}$ are well-researched, there is a lack of knowledge whether GnRHa treatment influences psychological functioning of treated children, despite the fact that prevention of psychological problems is used as one of the main reasons for treatment initiation. In the present study we seek to address this issue by exploring differences in cognitive function, behavior, emotional reactivity, and psychosocial problems between $\mathrm{GnRHa}$ treated CPP girls and age-matched controls. Fifteen girls with idiopathic CPP; median age 10.4 years, treated with slow-release GnRHa (triptorelin acetate-Decapeptyl $\mathrm{SR}^{\circledR}$ 11.25) and 15 age-matched controls, were assessed with a comprehensive test battery consisting of paper and pencil tests, computerized tasks, behavioral paradigms, heart rate variability, and questionnaires filled in by the children's parents. Both groups showed very similar scores with regard to cognitive performance, behavioral and psychosocial problems. Compared to controls, treated girls displayed significantly higher emotional reactivity ( $p=0.016$; Cohen's $d=1.04$ ) on one of the two emotional reactivity task conditions. Unexpectedly, the CPP group showed significantly lower resting heart rates than the controls ( $p=0.004$; Cohen's $d=1.03$ ); lower heart rate was associated with longer treatment duration $(r=-0.582$, $p=0.037$ ). The results suggest that GnRHa treated CPP girls do not differ in 
their cognitive or psychosocial functioning from age matched controls. However, they might process emotional stimuli differently. The unexpected finding of lower heart rate that was associated with longer duration of the treatment should be further explored by methods appropriate for assessment of cardiac health.

Keywords: central precocious puberty, gonadotropin releasing hormone analog, cognitive function, emotion regulation, psychosocial function, heart rate variability, puberty

\section{INTRODUCTION}

Central precocious puberty (CPP) is defined as the advent of an otherwise normal puberty before the age of 8 years in girls and 9 years in boys due to premature activation of the hypothalamicpituitary-gonadal (HPG) axis (Nebesio and Eugster, 2007). The etiology of CPP is unclear and varies with gender. It is predominantly found in girls and while the majority of female CPP is idiopathic, in boys it is more frequently secondary to an organic cause (e.g., tumor; Choi et al., 2013). CPP incidence is age dependent. Danish data from 1993 to 2001 showed an incidence of 8:10,000 in girls aged 5-9 and 1-2:10,000 in boys aged 8-10 (Teilmann et al., 2005).

CPP is associated with early bone maturation and reduced adult height in the youngest cases. Pharmacological blockade of the gonadotropin stimulus with GnRH analogs (GnRHa), which leads to cessation of gonadal sex hormones production, is nowadays considered the standard treatment for CPP (Carel et al., 2009); the main treatment goals are an increase in adult height and prevention of psychological problems (Sonis et al., 1985; Johansson and Ritzen, 2005; Tremblay and Frigon, 2005). While research shows that treatment can positively influence adult height in treated girls, especially if started before 6 years of age (Carel et al., 2009), the effects in boys and with regard to psychological functioning are less explored. Both a recent consensus statement and an update on the usage of GnRHa in CPP strongly emphasize the need for more research regarding GnRHa effects on psychological functioning (Carel et al., 2009; Chen and Eugster, 2015).

GnRHa treatment can potentially influence CPP children's psychological functioning through several pathways. Firstly, postponement of the pubertal development by blockade of sex hormones production can reduce psychological distress associated with early biological maturation. Secondly, abolition of sex hormone influences on the developing brain may on its own have an effect on cognitive development. Finally, GnRHa can potentially influence cognitive development via $\mathrm{GnRH}$ receptors that are widely present in brain areas not related to reproduction (Skinner et al., 2009). Several human and animal studies suggest that GnRHa may indeed influence cognitive functioning. A decline in working and episodic verbal memory associated with GnRHa treatment has been observed in women with benign leiomyomata uteri and endometriosis (Grigorova et al., 2006; Craig et al., 2007). In an animal study, using an ovine model of pubertal development, prepubertal GnRHa treatment significantly affected emotion regulation capacity, reward seeking behavior, and emotional reactivity in young sheep (Wojniusz et al., 2011; Evans et al., 2012). Furthermore, GnRHa treatment significantly and sex-specifically affected hippocampus and amygdala gene expressions and altered amygdalae volumes in the same animals (Nuruddin et al., 2013a,b,c). In addition, possible effects of $\mathrm{GnRHa}$ on cardiac health have recently been postulated, following findings of increased prevalence of cardiovascular disease in prostate cancer patients treated with GnRHa (Tsai et al., 2007; Keating et al., 2010).

The consensus statements and findings from adult and animal studies warrant a broader investigation of cognitive and emotional functioning in GnRHa treated CPP children. In the current study we, therefore, compared CPP girls under GnRHa treatment to age-matched controls. We assessed children's cognitive function by using a comprehensive neuropsychological test battery consisting of paper and pencil and computerized tests. Additionally, we assessed cognitive, social, and behavioral function at home and school situations by employing questionnaires completed by the children's parents. Since animal twin studies indicated poorer emotional regulation capacity and higher emotional reactivity in $\mathrm{GnRHa}$ treated lambs compared to their untreated twins (Wojniusz et al., 2011; Evans et al., 2012), assessment of emotional processing was additionally included in the study. We employed the emotional flanker task (EFT) for the assessment of emotional reactivity (Bishop et al., 2004) and calculated vagally mediated heart rate variability (HRV) as a measure of emotional regulation capacity (Appelhans and Luecken, 2006; Thayer and Lane, 2009; Koval et al., 2013).

\section{MATERIALS AND METHODS}

\section{Participants}

Clinical records of girls with idiopathic CPP, treated with GnRHa between November 2009 and December 2011, either at the University Hospital Ghent or the University Hospital Brussels, were reviewed. CPP was defined according to the combination of the following three items: (a) the onset of breast development before the age of 8 years; (b) accelerated growth velocity in the months before diagnosis; and (c) advancement of bone age by at least one year compared to chronological age. In cases with uncertain diagnosis, a standardized LHRH test (applied in 12 out of 15 girls) yielding an $\mathrm{LH}$ peak above $4.5 \mathrm{U} / \mathrm{l}$ and the finding of an estrogenized uterus (corpus length/cervix length $>1$ ) on pelvic ultrasound were considered as additional evidence for the presence of CPP. A minimum age of 9 years (due to the complexity of the test package), treatment by GnRHa for at least 6 months, and 2-3 monthly clinical follow-up was mandatory to enter the study. 
GnRHa treatment was adjusted in case of incomplete pubertal suppression as judged by physical examination and LH/FSH blood sampling or repeated GnRH testing. At the time of the study, puberty suppression was determined clinically and radiologically as successful in all patients based on Tanner stage (no progression of breast development), growth velocity (decreased as compared to pre-treatment), and bone age. Exclusion criteria were additional endocrine or other chronic diseases, which could influence cognitive and behavioral function; learning difficulties, defined as an IQ $<70$; and non-European descent due to race/ethnicity based differences concerning age of pubertal onset (Biro et al., 2013). On the basis of these criteria, two girls out of 17 were excluded. Fifteen healthy controls, carefully matched for age, were recruited through flyers distributed in public places. All patients and controls gave their assent, and parents gave written informed consent. The study was approved by the ethical committees of both institutions; Commissie Medische Ethiek UZ Gent and Commissie Medische Ethiek UZ Brussel.

\section{Procedures}

Patients and controls were invited to either the University Hospital Ghent or Brussels. After assessment of medical history and physical examination including anthropometrics and pubertal staging by an experienced pediatric endocrinologist, bone age was assessed from an X-ray of the left hand and wrist by one single investigator (MC) according to the Greulich and Pyle method. All CPP patients and controls underwent neuropsychological assessments, an emotional reactivity test, and heart rate monitoring for calculation of HRV. Behavioral questionnaires were completed by parents. All neuropsychological tests were applied by one single psychologist (NC), experienced in pediatric clinical psychology, and trained in test administration and scoring, and consisted of a range of cognitive, behavioral, and neuropsychological assessments. Heart rate monitoring, EFT and computer based cognitive tests (CANTAB) were supervised by the same investigator (SW) in all participants. In total, tests took $\sim 2.5 \mathrm{~h}$ to complete. The girls were offered two breaks and soft drinks in between the testing blocks and a small financial compensation for participation in the study.

\section{Neuropsychological Tests and Questionnaires Intellectual Level}

An abbreviated version of the Wechsler Intelligence Scale for Children-III (WISC-III) was used to generate an estimate of general cognitive ability. Two verbal (Vocabulary and Information) and two performance subtests (Block Design and Picture Completion) were used. This short-form combination has been shown to have a high reliability (Atkinson and Yoshida, 1989).

\section{Memory Tests}

The Rey Auditory Verbal Learning Test [RAVLT; Dutch version: (Saan and Deelman, 1986)] was used to evaluate auditoryverbal memory. The recognition component was not assessed in this study. We derived five scores: Immediate Memory, Best Memory, Proactive Interference, Retroactive Interference, and Delayed Recall. We also computed two combined scores which are frequently used in studies that employ RAVLT: Learning Rate, reflecting the learning ability of the subject, and Total Learning, representing the capacity to recall and accumulate words across learning trials.

The Continuous Visual Memory Test (CVMT; Trahan and Larrabee, 1988) measures visual learning and memory, i.e., acquisition of information and retention over time (storage and retrieval). Acquisition or short-term memory included Immediate Memory and Proactive Interference scores, as well as Learning Rate score. Storage includes the CVMT Recognition score. Retrieval from long-term storage included Delayed Recall, Retroactive Interference, Best Learning, and Total Learning scores on both the RAVLT and CVMT.

\section{Spatial Ability}

The Mental Rotation Test in which the subject was asked to compare two $3 \mathrm{D}$ objects and state if they are the same images (non-mirror or mirror images) was an adapted version of the task used by Hugdahl et al. (2006), originally developed by Shepard and Metzler (1971). The test had 20 pairs of images, the subjects were judged on how accurately, and rapidly they could distinguish between the pairs. The task has not been specifically validated for use in children, however in our sample the children performed similarly to what has been observed in adults.

\section{Executive Function and Attention}

A selection of four tests from the Delis-Kaplan Executive Function System (Delis et al., 2001) was used to assess different aspects of executive functions; the Trail Making Test, the Verbal Fluency Test, the Color Word Interference Test, and the Design Fluency Test. Composite executive functioning and processing speed domain scores are expressed as mean of subscale $z$-scores.

Additionally a selection of four tests from the Cambridge Neuropsychological Test Automated Battery (CANTAB), provided by Cambridge Cognition Ltd. was used to further assess executive function and attention. CANTAB tests are computerized, giving higher chance to discover minor differences between the groups. Although CANTAB tests were originally developed to assess patterns of cognitive decline in adults, their applicability for usage in children in age group 5-12 has been previously confirmed (Luciana and Nelson, 2002). The following tests were included:

Choice reaction time (CRT) is a 2 -choice reaction time test with stimulus and response uncertainty introduced by having two possible stimuli (left and right arrows) and two possible responses (left and right buttons). Mean correct response latency and percentage of correct responses were recorded as outcome measures.

Match to sample visual search (MTS) is a matching test, with a speed/accuracy trade-off. The subject is presented with a sample-stimulus figure, composed of four colored elements displayed in the middle of the screen. After a brief delay, a varying number of similar patterns $(1,2,4$, or 8$)$ are shown 
around the edge of the screen with only one of them matching the sample-stimulus pattern. The subject has to touch the matching pattern as fast as possible on the screen. Mean correct response time and percentage of correct responses were used as outcome measures.

Spatial working memory (SWM) tests subject's ability to retain spatial information and to manipulate remembered items in working memory. A number of colored boxes are shown on the screen. By process of elimination, the subject should find one blue "token" in each of a number of boxes. The number of boxes is gradually increased from three to eight boxes and the color and position of the boxes are changed from trial to trial to discourage the use of stereotyped search strategies. Total number of errors and SWM Search Strategy were used as outcome measures.

Stop signal task (SST) is a response inhibition test, giving a measure of an individual's ability to inhibit a pre-potent response. The subject is told to press the button that corresponds to the direction of the arrow presented on the computer screen, but, if they hear an auditory signal, they should withhold their response. There are five assessed blocks, each of 64 trials. The last four blocks were subjected to statistical analysis. The main outcome measure was the Stop Signal Response Time (SSRT), which is an estimate of the latency of the stop process. Additionally, the probability of inhibiting the response when signal occurred was calculated.

\section{Parental Questionnaires}

The Behavior Rating Inventory of Executive Function (BRIEF)-the parent version (Dutch translation Smidts and Huizinga, 2009) assesses children's cognitive and behavioral aspects of executive function in home situations. It includes eight non-overlapping clinical scales (Inhibit, Initiate, Organization of Materials, Shift, Working Memory, Monitor, Emotional Control, Plan/Organize) and two validity scales (Negativity and Inconsistency of responses)

The Child Behavior Check List-4-18 years (Dutch translation: Verhulst and Van der Ende, 2004) is a standardized measure of academic, social competence, and behavioral problems. The questionnaire is completed by parents and includes eight subscales: Withdrawn, Somatic complaints, Anxious/Depressed, Social Problems, Thought Problems, Attention Problems, Delinquent Behavior, and Aggressive Behavior. The first three subscales add up to the Internalizing Problems scale and the last two to the Externalizing Problems scale. Finally, the overall Total Problems scale consists of all items. Additionally a Social Competence scale is derived from items grouped into Activities, Social, and School constructs. For each scale, $T$-scores (mean = $50 \pm 10$ ) can be obtained. A clinical cut-off point on the Total, the Internalizing and the Externalizing score was set at $T=60$.

\section{Socioeconomic Indicators}

Two socioeconomic indicators for parental occupations were used. An occupational class was constructed on the basis of International Standard Classification of Occupations (ISCO08) (ILO, 1990) namely (1) managers and professionals; (2) technicians, clerks, and service workers; and (3) craft workers, machine operators, and elementary occupations. The number of years of formal education was divided into three groups: Secondary school, Higher education Short Type, and Higher Education Long Type or University.

\section{Emotion Processing}

\section{The Emotional Flanker Task (EFT)}

EFT was used to assess emotional reactivity. The task is an adapted version based on previous studies (Bishop et al., 2004). With an inter-trial interval of $1000 \mathrm{~ms}$, on each trial, two faces and two houses were presented in horizontal and vertical pairs, respectively (Figure 1). Participants were instructed to decide as fast as possible whether the presented buildings were identical or not, and to respond by pressing a corresponding response button. They were informed that the faces presented in the periphery were irrelevant and didn't need to be attended to. If a participant did not make a choice within the first $4 \mathrm{~s}$, the next trial was automatically presented. After five practice trials, participants were exposed to 207 trials, starting with three consecutive trials with neutral flankers to increase the effects of emotional flankers (Bishop et al., 2004). Out of the remaining 204 trials, target stimuli (houses) were identical in 50\% of the trials; in $35 \%$ of all presentation trials flanker stimuli consisted of anxious faces, and in $65 \%$ of trials of faces with neutral expressions. The lower proportion of emotional flankers was chosen to increase the stimulus valence and resulting reactivity to these trials (Bishop et al., 2004).

The main outcome measure was a flanker-valence effect (FVE), which was calculated by subtraction of reaction times in the valence condition "neutral" from valence condition "anxious." Larger reaction time differences between distractor valences "neutral" and "anxious" were interpreted as higher emotional reactivity (Grose-Fifer et al., 2013). To avoid confounding biases caused by different processing of identical

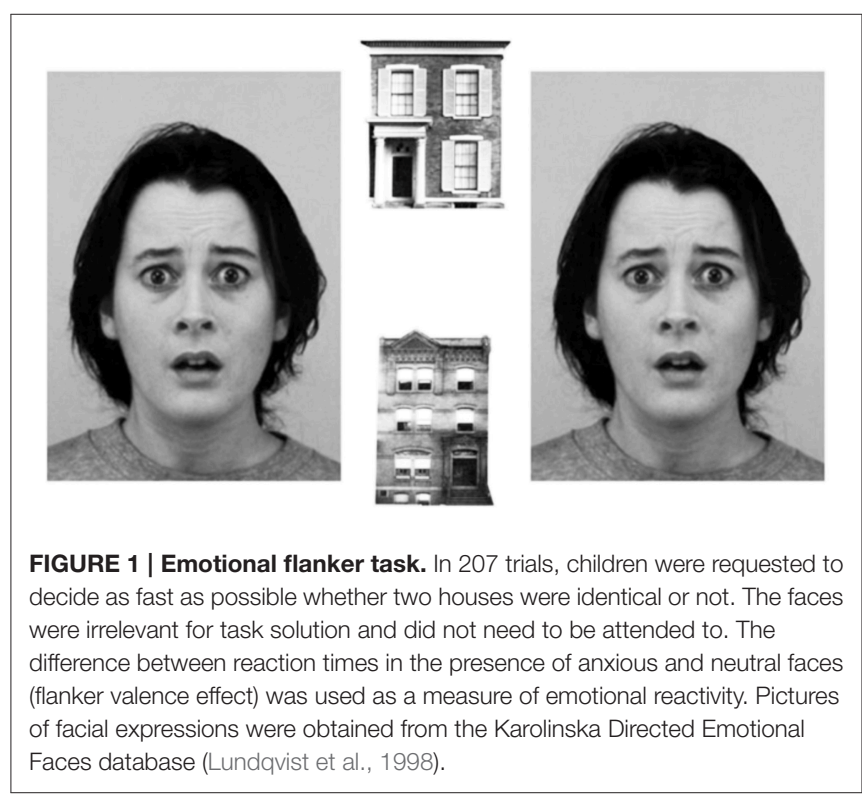


and non-identical target stimuli, behavioral analyses were done separately for both conditions. Only correct responses were analyzed.

\section{Heart Rate and Heart Rate Variability (HRV)}

HRV has been extensively used in psychophysiological research to assess emotion regulation capacity (Thayer et al., 2012). Heart rate $(\mathrm{HR})$ and $\mathrm{HRV}$ were calculated from the inter-beat intervals (IBIs), recorded with a sampling rate of $1000 \mathrm{~Hz}$, using the Polar $R S 800^{\circledR}$ monitor. After a Polar belt was placed around the participant's chest, she was seated in a comfortable chair and asked to relax for $10 \mathrm{~min}$ (baseline). Thereafter, she was led over to a computer station and performed the EFT. The recording was stopped after task completion. Altogether, 20 min IBI-recordings of 29 out of 30 participants were collected. IBI recordings of one CPP girl were invalid due to equipment failure. Prior to analysis, all recordings were cleared of artifacts using ARTiiFACT software (Kaufmann et al., 2011). A minimum requirement of $95 \%$ of artifact-free IBIs was set as an inclusion criterion. No participant exceeded the $5 \%$ artifact-threshold; however there was a significantly higher mean number of artifacts in the treatment group $(M=7.1, S D=4.4)$ vs. controls $[M=2.3$, $\left.S D=3.6 ; t_{(27)}=3.2, p=0.003\right]$. Five minute-periods of data from the baseline and the EFT conditions, respectively, were chosen for further analyses, according to the Task Force (1996) guidelines (1996). HR and Root Mean Square of Successive IBIs (RMSSD) were analyzed as time domain measures. Additionally, power spectral density of High (HF), frequency was analyzed using Fast Fourier transformation following guidelines of the Task Force (1996). Frequency spectrum data were normalized by logarithmic transformation. Recordings from baseline and during EFT were analyzed separately.

\section{Statistical Analysis}

SPSS (version 20) was used for statistical analyses. Due to a relatively low number of participants, resampling of data, applying bias-corrected and accelerated bootstrapping technique (5000 resamples) was used to control for data stability. For comparisons between the groups, independent sample $t$-tests were applied, while a paired sample $t$-test was used to assess the differences between repeated measurements. If differences between groups were significant, Cohen's $d$ was calculated for effect size estimation. Partial correlations were used to explore the associations between treatment duration and cardiac measures and behavioral test while controlling for chronological age. Group differences in socioeconomic status were assessed by comparing the educational levels of children's parents using Fisher's exact test.

\section{RESULTS}

The clinical characteristics of CPP girls and controls are summarized in Table 1. Eleven out of 15 girls had started treatment with $11.25 \mathrm{mg}$ intramuscular injection of GnRHa (Decapeptyl SR ${ }^{\circledR}$ ) every 10 th week, and 4 out of 15 girls with a $3.75 \mathrm{mg}$ injection every 4 th week. Patients were monitored regularly and their medication was adjusted in case of incomplete pubertal suppression as judged by physical examination and LH/FSH blood sampling or repeated GnRH testing; $11.25 \mathrm{mg}$ every 8 weeks in three girls, $11.25 \mathrm{mg}$ every 6 weeks in one girl, $11.25 \mathrm{mg}$ every 10 weeks in two girls (from 3.75/per 4 weeks), and $11.25 \mathrm{mg}$ every 12 weeks in one girl. At study entry (T1), 14 out of 15 girls had a Tanner score for breast development equal to or less than at the start of the treatment. Median duration of GnRHa treatment was 28 months (range: 8-57) at the time of the study. As expected, body height, BMI and bone age were still higher in treated CPP girls as compared to controls. Over the course of treatment, the difference between bone age (BA) and chronological age (CA) was reduced by 8.6 months, $\left[t_{(14)}=2.2, p=0.042\right]$. Whereas all control girls were healthy, one CPP girl suffered from chronic otitis media and one from hip dysplasia, independently of the CPP and GnRHa treatment.

\section{Neuropsychological Findings}

Table 2 summarizes the results of the neuropsychological assessment. The mean estimated IQ was 94 (range: 73-116) for CPP girls and 102 (range 81-125) for control girls; the difference was not significant. The estimated IQ scores were consistent with the school situation; 26/30 girls were attending an appropriate grade for their age. Two girls from the control group and two girls from the CPP group were delayed by 1 year at school. No associations were found between IQ scores and duration of GnRHa therapy. The statistical comparison of parental educational level (Fisher's exact test) showed no significant difference between groups (Table 1).

Regarding verbal (RAVLT) and non-verbal memory tests (CVMT), both groups performed very similarly, showing no significant differences. The four CANTAB tests targeting attention and executive function are sensitive to small differences in performance. Nevertheless, both groups showed very similar scores on all four tests, showing no significant differences. There were no significant between-group differences on the composite $z$-scores of cognitive executive function and processing speed except for the Trail Making Test-Number Sequencing, where CPP girls performed worse than controls $\left[t_{(28)}=2.8, p=0.01, d\right.$ $=1.32]$. The BRIEF questionnaire scores showed no significant differences regarding parental reported executive function (Table 3).

\section{Behavioral and Emotional Problems (CBCL)}

Overall, the CBCL results (Table 3) showed that CPP girls did not have significantly more behavioral problems than controls and they displayed similar social competence. When compared to normal range $(T=50 \pm 10)$, the most elevated scores were observed within internalizing problems domain on withdrawn, somatic complaints and anxious/depressed subscales. Out of 15 CPP girls, two had elevated scores at a clinically meaningful level $(T>60)$ on all of these four scales apart from somatic complains where four out of 15 had a $T$-score $>60$. Similarly, in the control group two girls showed elevated $T$-scores on each of the same scales. 
TABLE 1 | Clinical characteristics of 15 girls with central precocious puberty (CPP) at the onset of gonadotropin releasing hormone analog therapy (T0) and at the moment of the study (T1), compared to 15 age-matched controls.

\begin{tabular}{|c|c|c|c|c|}
\hline Clinical characteristics & CPP (T0) & CPP (T1) & Control & $p$ \\
\hline CA (years) & $7.5(4.4 ; 9.8)$ & $10.4(9.2 ; 11.8)$ & $10.3(9.1 ; 11.4)$ & 0.877 \\
\hline Height (z-score) & $0.9(-0.7 ; 3,1)$ & $0.8(-0.4 ; 3.2)$ & $0.3(-2.8 ; 1.6)$ & 0.023 \\
\hline Weight (z-score) & $0.7(-0.8 ; 2.4)$ & $0.8(0.0 ; 2.5)$ & $-0.5(-2.0 ; 1.2)$ & 0.001 \\
\hline $\mathrm{BMI}\left(\mathrm{kg} / \mathrm{m}^{2}\right)$ & $17.0(15.0 ; 30.0)$ & $18.0(15.0 ; 34.0)$ & $16.0(13.0 ; 20.0)$ & 0.055 \\
\hline BA (years) & $9.4(7.8 ; 13.0)$ & $11.5(10.0 ; 13.0)$ & $9.3(7.8 ; 12.0)$ & $<0.001$ \\
\hline$\triangle \mathrm{BA}-\mathrm{CA}$ & $2.0(0.3 ; 4.8)$ & $1.3(-0.4 ; 3.2)$ & $-1.0(-2.0 ; 1.7)$ & $<0.001$ \\
\hline \multirow[t]{4}{*}{ Tanner stage M (n) and P (n) } & & $\mathrm{M} 1=6 ; \mathrm{P} 1=4$ & $M 1=10 ; P 1=14$ & \\
\hline & & $\mathrm{M} 2=3 ; \mathrm{P} 2=5$ & $\mathrm{M} 2=3 ; \mathrm{P} 2=0$ & \\
\hline & & $M 3=6 ; P 3=5$ & $\mathrm{M} 3=2 ; \mathrm{P} 3=1$ & \\
\hline & & $M 4=0 ; P 4=1$ & $\mathrm{M} 4=0 ; \mathrm{P} 4=0$ & \\
\hline
\end{tabular}

\begin{tabular}{|c|c|c|c|}
\hline Socio-economic background & CPP (T1) & Control & \\
\hline \multicolumn{4}{|l|}{ EDUCATION } \\
\hline Mother: S/H1/H2 & $47 / 33 / 20 \%$ & $23 / 62 / 15 \%$ & 0.307 \\
\hline Father: S/H1/H2 & $33 / 47 / 20 \%$ & $29 / 57 / 14 \%$ & 0.842 \\
\hline \multicolumn{4}{|l|}{ OCCUPATION MOTHER } \\
\hline Manager or professional & $27 \%$ & $69 \%$ & \\
\hline Technicians, clerks and service workers & $60 \%$ & $31 \%$ & \\
\hline Craft workers, machine operators, elementary occupations & $13 \%$ & $0 \%$ & \\
\hline \multicolumn{4}{|l|}{ OCCUPATION FATHER } \\
\hline Manager or professional & $33 \%$ & $38 \%$ & \\
\hline Technicians, clerks and service workers & $40 \%$ & $31 \%$ & \\
\hline Craft workers, machine operators, elementary occupations & $27 \%$ & $31 \%$ & \\
\hline
\end{tabular}

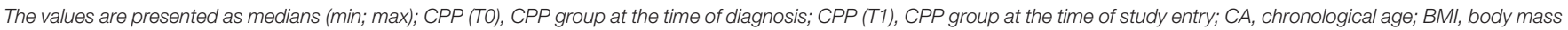

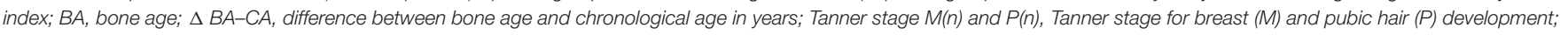

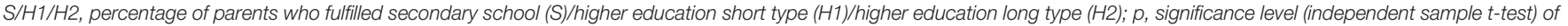
difference between CPP (T1) and Control for continuous variables and Fisher's exact test for education.

\section{Emotional Reactivity}

Mean reaction times in EFT for all four $(2 \times 2)$ conditions (range: $1062-1319$ ms) were comparable to adult data of similar versions of this task (Bishop et al., 2004). In trials with non-identical targets (mismatch-condition) reaction times were generally slower, although not significantly, in both groups compared to identical target condition (data not shown). Interestingly, for the non-identical target condition the main outcome measure, calculated as difference in reaction times in presence of "neutral" and "anxious" faces (FVE), showed a significant distractionrelated slow-down of motor response in the CPP group (FVE = $36.9 \mathrm{~ms}, S D=93.3$ ), whereas response facilitation was seen in controls $\left[\mathrm{FVE}=-42.7 \mathrm{~ms}, S D=75.5 ; t_{(28)}=-2.6, p=0.016, d\right.$ $=1.04]$. In trials with identical targets, the groups did not differ significantly in their distractibility, showing distraction related response facilitation in both the control $(\mathrm{FVE}=-8.3 \mathrm{~ms}, S D=$ 68.6) and the CPP group [FVE $=-71.7, S D=83.4 ; t_{(28)}=1.2$, $p=0.238]$.

\section{Heart Rate and Heart Rate Variability}

Under resting conditions, HR was significantly lower in the CPP group $(\mathrm{HR}=76.4 / \mathrm{min}, S D=5.5)$ as compared to controls [HR $\left.=87.7 / \mathrm{min}, S D=10.9 ; t_{(27)}=3.5, p=0.004, d=-1.03\right]$.
HRV parameters showed significantly higher values for the CPP group as compared to controls: RMSSD $72.4(S D=19.1)$ vs. 43.8 $(S D=19.7), t_{(27)}=-3.9, p=0.004, d=1.44$, and $\operatorname{Ln}(\mathrm{HF}) ; 7.5$ $(S D=0.6)$ vs. $6.6(\mathrm{SD}=1.0), t_{(27)}=-3.1, p=0.004, d=0.95$. The same pattern was evident when participants performed the EFT paradigm (data not shown).

\section{Effect of Treatment Duration}

Partial correlation (controlled for age) between treatment duration and heart rate revealed that longer treatment duration was associated with lower mean heart rate, $r=-0.58$, $p=0.037$ (Figure 2). No significant correlations between treatment duration and any of the HRV or EFT measures were found.

\section{Post-hoc Power Analyses}

In order to estimate the probability of falsely rejecting the null hypothesis, the power of the study was calculated post-hoc. The majority of the neuropsychological tests and questionnaires used in this study refer to norm data expressed in form of standardized, scaled or T scores, where a difference of more than one standard deviation from the population mean is considered to be clinically significant. Consequently, for independent sample 
TABLE 2 | Cognitive function of girls with central precocious puberty (CPP) treated with gonadotropin releasing hormone analog therapy, compared to age-matched controls.

\begin{tabular}{|c|c|c|c|}
\hline & $\begin{array}{c}\text { CPP } \\
N=15\end{array}$ & $\begin{array}{l}\text { Controls } \\
N=15\end{array}$ & $p$ \\
\hline \multicolumn{4}{|l|}{ IQ (WISC III) } \\
\hline Total IQ & $94.1(12.1)$ & $101.9(12.0)$ & 0.09 \\
\hline Performance & $96.8(7.8)$ & $103.2(11.2)$ & 0.08 \\
\hline Verbal IQ & $98.4(10.7)$ & $101.6(9.4)$ & 0.39 \\
\hline WISC information & $10.9(2.2)$ & $10.7(1.9)$ & 0.80 \\
\hline WISC vocabulary & $9.1(2.6)$ & $10.5(1.7)$ & 0.09 \\
\hline WISC incomplete pictures & $7.7(3.2)$ & $10.1(4.0)$ & 0.07 \\
\hline WISC bloc design & $8.5(3.0)$ & $9.8(3.4)$ & 0.30 \\
\hline \multicolumn{4}{|l|}{ MEMORY } \\
\hline \multicolumn{4}{|l|}{ Verbal (RAVLT) } \\
\hline Trial 1 (immediate memory) & $6.2(1.9)$ & $7.1(1.9)$ & 0.23 \\
\hline Trial 2 & $9.0(2.4)$ & $10.2(2.7)$ & 0.22 \\
\hline Trial 3 & $9.8(3.7)$ & $11.7(1.6)$ & 0.08 \\
\hline Trial 4 & $12.3(1.9)$ & $13.2(2.1)$ & 0.21 \\
\hline Trial 5 (best memory) & $12.7(1.9)$ & $12.9(2.2)$ & 0.80 \\
\hline Learning rate & $6.5(1.8)$ & $5.9(2.2)$ & 0.38 \\
\hline Total learning & $50.1(9.3)$ & $55.1(8.5)$ & 0.13 \\
\hline Proactive interference & $5.7(1.1)$ & $6.1(2.9)$ & 0.70 \\
\hline Retroactive interference & $11.7(2.2)$ & $11.3(2.9)$ & 0.62 \\
\hline Delayed recall & $11.1(3.4)$ & $11.1(2.7)$ & 1.00 \\
\hline \multicolumn{4}{|l|}{ Visual (CVMT) } \\
\hline Total score & $108.7(18.3)$ & $114.4(16.1)$ & 0.40 \\
\hline Recognition & $4.2(1.8)$ & $4.7(1.2)$ & 0.42 \\
\hline \multicolumn{4}{|l|}{ MENTAL ROTATION } \\
\hline Number correct (out of 20) & $14.6(2.4)$ & $14.3(2.3)$ & 0.77 \\
\hline Total time (s) & $160.3(63.3)$ & $189.3(62.3)$ & 0.22 \\
\hline \multicolumn{4}{|l|}{ COGNITIVE EXECUTIVE FUNCTION } \\
\hline Trail Making Test: shifting & $9.3(3.7)$ & $11.4(2.5)$ & 0.07 \\
\hline Color-Word Interference Test: shifting & $11.2(2.4)$ & $10.5(3.0)$ & 0.50 \\
\hline $\begin{array}{l}\text { Color-Word Interference Test: } \\
\text { interference }\end{array}$ & $11.3(2.2)$ & $11.5(3.5)$ & 0.86 \\
\hline Verbal Fluency Test: shifting & $12.9(2.9)$ & $12.6(3.3)$ & 0.77 \\
\hline Design Fluency Test: shifting & $12.1(2.1)$ & $12.3(3.2)$ & 0.79 \\
\hline Composite $z$-score & $-0.09(0.9)$ & $0.09(1.1)$ & 0.64 \\
\hline \multicolumn{4}{|l|}{ PROCESSING SPEED } \\
\hline Trail Making Test: number sequencing & $8.0(3.3)$ & $10.9(2.2)$ & 0.01 \\
\hline Trail Making Test: letter sequencing & $9.4(3.1)$ & $9.4(3.1)$ & 1.00 \\
\hline $\begin{array}{l}\text { Color-Word Interference Test: color } \\
\text { reading }\end{array}$ & $10.0(2.6)$ & $10.5(2.7)$ & 0.59 \\
\hline $\begin{array}{l}\text { Color-Word Interference Test: word } \\
\text { reading }\end{array}$ & $11.2(1.4)$ & $11.3(2.3)$ & 0.85 \\
\hline Verbal Fluency Test: category fluency & $11.7(2.9)$ & $12.1(2.8)$ & 0.72 \\
\hline Verbal Fluency Test: letter fluency & $8.9(1.9)$ & $8.3(2.1)$ & 0.42 \\
\hline Design Fluency Test: filled dots & $10.4(3.0)$ & $11.7(2.0)$ & 0.19 \\
\hline Design Fluency Test: empty dots & $11.3(2.7)$ & $12.3(3.9)$ & 0.45 \\
\hline Composite $z$-score & $-0.20(1.1)$ & $0.2(0.9)$ & 0.29 \\
\hline \multicolumn{4}{|c|}{ ATTENTION AND EXECUTIVE FUNCTION (CANTAB) } \\
\hline $\begin{array}{l}\text { Choice reaction time: correct } \\
\text { responses (\%) }\end{array}$ & $98.4(1.3)$ & $99.0(1.1)$ & 0.18 \\
\hline
\end{tabular}

(Continued)
TABLE 2 | Continued

\begin{tabular}{|c|c|c|c|}
\hline & $\begin{array}{c}\text { CPP } \\
N=15\end{array}$ & $\begin{array}{l}\text { Controls } \\
N=15\end{array}$ & $p$ \\
\hline $\begin{array}{l}\text { Choice reaction time: mean } \\
\text { latency (ms) }\end{array}$ & $469.6(107.9)$ & $492.4(112.1)$ & 0.57 \\
\hline $\begin{array}{l}\text { Match to sample visual search: } \\
\text { correct responses (\%) }\end{array}$ & $98.1(2.0)$ & $98.9(1.7)$ & 0.23 \\
\hline $\begin{array}{l}\text { Match to sample visual search: mean } \\
\text { latency (s) }\end{array}$ & $3.4(0.7)$ & $3.7(1.0)$ & 0.29 \\
\hline $\begin{array}{l}\text { Spatial working memory: number of } \\
\text { errors }\end{array}$ & $30.7(14.6)$ & $26.5(19.3)$ & 0.50 \\
\hline $\begin{array}{l}\text { Spatial working memory: search } \\
\text { strategy }\end{array}$ & $32.7(5.4)$ & 34.1 (6.2) & 0.52 \\
\hline $\begin{array}{l}\text { Stop signal task: successful stops } \\
(\%)\end{array}$ & $47.3(7.4)$ & $50.1(9.8)$ & 0.30 \\
\hline Stop signal response time (ms) & 205.8 (53.2) & $214.9(55.1)$ & 0.64 \\
\hline \multicolumn{4}{|c|}{$\begin{array}{l}\text { IQ estimations are presented as standardized IQ scores (normative mean }=100, S D= \\
\text { 15). WISC subscales, Cognitive executive function and Processing speed are presented } \\
\text { as scaled scores (normative mean = 10, SD = 3). CANTAB, Memory, and Mental } \\
\text { rotation tests results are presented as raw scores; WISC, Wechsler Intelligence Scale for } \\
\text { Children; RAVLT, Rey Auditory Verbal Learning Test; CVMT, Continuous Visual Memory } \\
\text { Test; CANTAB, Cambridge Neuropsychological Test Automated Battery; p, significance } \\
\text { level (independent sample t-test) of difference between CPP and controls. } p<0.05 \text { are } \\
\text { marked in bold. }\end{array}$} \\
\hline
\end{tabular}

$t$-test, statistical power $(1-\beta)$ was found to be 0.75 , based on an $\alpha$ level of 0.05 and a difference of one standard deviation between the groups (Faul et al., 2007).

\section{DISCUSSION}

The main objective of the study was to assess psychological functioning in GnRHa treated girls with idiopathic CPP as compared to age-matched controls. With respect to cognitive functioning, behavioral, and social problems, treated CPP girls do not differ from age matched controls. However, the significance of the results regarding emotional reactivity and emotional regulation capacity remains unclear. The interpretation of HRV findings, as a measure of emotional regulation capacity, is complicated by the fact that GnRHa may directly influence heart rhythm through GnRH cardiac receptors (Dong et al., 2011). Possible interpretations of our findings as well as methodological challenges are discussed below.

\section{Cognitive Functioning and Psychosocial Problems}

In contrast to previous reports on elevated verbal IQ scores, and/or accelerated school achievements in CPP girls (Galatzer et al., 1984; Ehrhardt and Meyer-Bahlburg, 1986), the GnRHa treated CPP girls' estimated IQ in the current study was within the normal range and somewhat lower, although not significantly, than that of controls (Table $\mathbf{1}$ ).

No significant differences between the CPP and the control group were seen with regard to cognitive performance neither on paper and pencil nor in computer based tests concerning memory, spatial ability, attention, and executive functions. Only in the Trail Making Test-Number Sequencing, assessing 
TABLE 3 | Cognitive executive function and behavioral problems in girls with central precocious puberty (CPP) treated with gonadotropin releasing hormone analog therapy, compared to age-matched controls.

\begin{tabular}{|c|c|c|c|}
\hline & $\begin{array}{c}\text { CPP } \\
N=14\end{array}$ & $\begin{array}{l}\text { Control } \\
N=10\end{array}$ & $p$ \\
\hline \multicolumn{4}{|l|}{ BRIEF } \\
\hline \multicolumn{4}{|l|}{ Clinical scales } \\
\hline Behavioral regulation index & $51.8(11.7)$ & $47.6(7.7)$ & 0.33 \\
\hline Inhibit & $52.1(9.8)$ & $48.9(10.6)$ & 0.47 \\
\hline Shift & $52.7(10.7)$ & $46.7(6.9)$ & 0.14 \\
\hline Emotional control & $50.1(10.6)$ & $48.3(6.8)$ & 0.65 \\
\hline Metacognition index & $50.7(10.1)$ & $49.1(10.4)$ & 0.71 \\
\hline Initiate & $50.5(7.2)$ & $46.5(5.3)$ & 0.15 \\
\hline Working memory & $52.5(11.0)$ & $47.7(9.0)$ & 0.26 \\
\hline Plan/organize & $49.1(9.0)$ & $49.7(9.1)$ & 0.88 \\
\hline Organization of materials & $48.3(7.7)$ & $49.5(11.2)$ & 0.77 \\
\hline Monitor & $48.7(7.1)$ & $50.3(8.8)$ & 0.62 \\
\hline Global executive composite & $51.3(9.8)$ & $48.1(10.5)$ & 0.46 \\
\hline \multicolumn{4}{|l|}{ Validity scales } \\
\hline Negativity & $0.5(0.9)$ & $0.2(0.6)$ & 0.36 \\
\hline \multirow[t]{2}{*}{ Inconsistency of Responses } & $2.0(1.4)$ & $1.9(1.7)$ & 0.90 \\
\hline & $N=15$ & $N=13$ & \\
\hline \multicolumn{4}{|l|}{ CBCL } \\
\hline Total social competence & $44.5(11.6)$ & $47.0(6.4)$ & 0.49 \\
\hline Activities & $41.4(9.0)$ & $44.5(6.6)$ & 0.31 \\
\hline Social & $45.9(7.4)$ & $47.7(6.3)$ & 0.51 \\
\hline School & $48.8(9.1)$ & $51.3(6.1)$ & 0.41 \\
\hline Internalizing problems & $56.7(10.9)$ & $53.5(11.1)$ & 0.45 \\
\hline Withdrawn & $55.2(8.3)$ & $55.2(6.6)$ & 0.99 \\
\hline Somatic complaints & $58.8(9.0)$ & $54.8(6.2)$ & 0.18 \\
\hline Anxious/Depressed & $58.1(9.8)$ & $56.3(8.5)$ & 0.61 \\
\hline Externalizing problems & $48.6(10.3)$ & $45.7(7.7)$ & 0.41 \\
\hline Delinquent behavior & $53.5(5.7)$ & $52.9(5.6)$ & 0.78 \\
\hline Aggressive behavior & $53.0(6.0)$ & $51.2(2.6)$ & 0.33 \\
\hline Total problems & $52.3(11.5)$ & $48.3(10.2)$ & 0.34 \\
\hline Social problems & $54.1(8.5)$ & $52.7(5.6)$ & 0.62 \\
\hline Thought problems & $53.7(6.7)$ & $52.7(6.7)$ & 0.68 \\
\hline Attention problems & $55.7(6.7)$ & $55.7(10.6)$ & 0.99 \\
\hline
\end{tabular}

Except for validity scales, all values are presented as T-scores (normative mean $=50$, $S D=10)$. BRIEF, Behavior Rating Inventory of Executive Function questionnaire, parent version; CBCL, Child Behavior Check List questionnaire, parent version; $p$, significance level (independent sample t-test) of difference between CPP and controls.

processing speed, the CPP group showed significantly poorer performance (Table 2). This finding is difficult to explain since neither the very similar Trail Making Test-Letter Sequencing, nor any other of the processing speed tests showed significant differences between the groups. Taking into account that the $p$-values were not corrected for multiple testing, it is possible that this finding is accidental. In line with this, the CPP girls' parents did not report any problems with regard to executive functioning as measured by the BRIEF questionnaire.

Behavioral problems and social competence were assessed with the parent version of the CBCL and showed no statistical

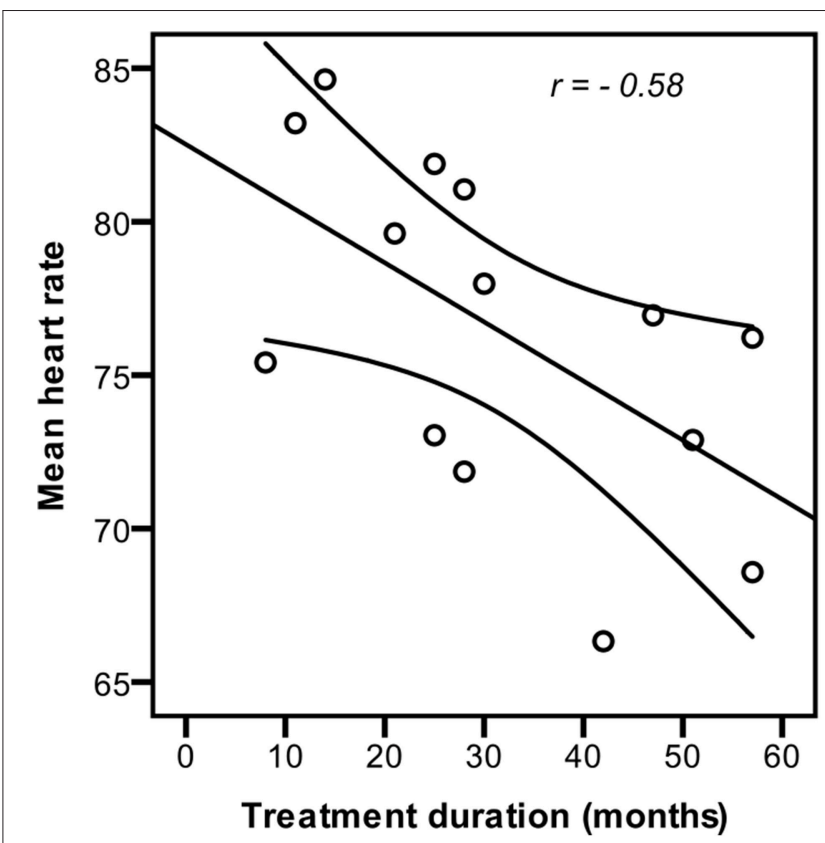

FIGURE 2 | Influence of treatment duration on heart rate. Longer GnRHa treatment duration was significantly correlated $(p=0.037)$ with lower resting heart rate (controlled for age) in girls with idiopatic central precocious puberty.

differences between the groups (Table 3). Several earlier studies reported different levels of problems in CPP using the CBCL. Based on CBCL scores of 33 girls with CPP compared to age matched controls, Sonis et al. (1985) concluded that overall they could be described as troubled, depressed, aggressive, socially withdrawn, and moody (Sonis et al., 1985). In their results, the authors did not discriminate between the idiopathic and other types of CPP. Moreover, at the time of CBCL scoring, only 8 out of 33 girls received GnRHa treatment, which at the beginning of the 1980s was still considered to be experimental; the results did not discriminate between the treated and untreated girls. In a longitudinal study, Xhrouet-Heinrichs et al. (1997) followed 20 girls with CPP (15 of idiopathic type) of which 15 were treated with GnRHa for 2 years. The CBCL was filled out by parents at 1 and 24 months after diagnosis. Authors reported elevated withdrawal, anxious/depressed, or aggressive behavior scores in $30-40 \%$ of the girls. After 2 years, most of the same girls still displayed elevated scores. In contrast, in our study, only 2 out of 15 (13\%) CPP girls showed elevated scores on the same scales, which was very similar to what we observed in age matched controls ( 2 out of 13). In a more recent study, Kim and Lee (2012) compared 34 girls with idiopathic CPP (mean age 8.1) to 39 same age controls; no information about whether CPP girls were treated was provided. The results showed that although CPP girls had more behavioral problems, no significant differences were observed between the two study groups in terms of clinically important scores.

While all of the presented studies differ with respect to the age of participants, treatment duration, and assessment time, it is worth mentioning that the most recent studies 
show less psychosocial problems in CPP children than older ones. Although speculative, the decrease in psychosocial problems reported in recent studies (including this one) could be a result of less stigmatization of and more openness about this condition and perhaps the modified management of CPP with regard to treatment initiation and monitoring.

\section{Emotional Processing Emotional Reactivity}

In the presence of fearful-faces in the mismatch-condition, CPP girls showed increased reaction times compared to neutral-faces, while the opposite was seen in the control group; in statistical terms this difference represented a large effect (Cohen, 1992). However, no significant differences between the groups were observed in the matched-condition.

In healthy samples, emotional stimuli can facilitate interference resolution, and enhance task performance by reducing reaction times (Levens and Phelps, 2008). In contrast, in vulnerable groups, increased reactivity toward emotionally intensive stimuli can be associated with increased interference between emotions and executive functions, leading to increased reaction times in a seemingly unrelated choice reaction task (for an overview see Mueller et al., 2011). Increased reaction time in the CPP group may therefore indicate higher distractibility by task-irrelevant stimuli (anxious faces) and increased interference with executive functions because processing of emotional (particularly negative) stimuli may impair executive motor control (de Houwer and Tibboel, 2010; Herbert and Sütterlin, 2011). Nevertheless, the fact that the same pattern was not observed in a matched-condition somewhat weakens such interpretation. While it is true that the mismatch-condition represents a higher cognitive demand, expressed by a tendency toward slower reaction times in both groups when compared to the matched-condition, we cannot firmly conclude that this minor difference in cognitive load is responsible for the diversity of outcomes. In summary, although part of the findings suggest differences in emotional reactivity between the groups, the results are not conclusive.

\section{Cardiac Function and Emotional Regulation}

GnRHa treated CPP girls had significantly lower resting HR and significantly higher HRV than controls. Resting HR was negatively correlated with treatment duration, i.e., longer $\mathrm{GnRHa}$ treatment was associated with lower resting HR (Figure 2), while no correlations between HRV and treatment duration were found. The results indicate large effects; Cohen's $d>0.8$ and Pearson's $r>0.5$ (Cohen, 1992).

The main goal of the heart rhythm recording was estimation of HRV as a proxy for cardiac vagal influence (Thayer et al., 2012). Consequently, the lower HR and higher HRV could suggest that treated CPP girls have better emotion regulation capacity and higher adaptability to changing contexts than controls. However, for such interpretation to be valid, a direct GnRHa effect on heart rhythm should be excluded. Such effect could be possibly mediated via GnRH receptors that have been found in cardiomyocytes (Kakar and Jennes, 1995). It has been shown in a murine model that GnRH can augment cardiomyocytes' contractile characteristics via a $\mathrm{GnRH}$ receptor/phosphokinase A-dependent (PKA) mechanism, while the opposite effect was observed after administration of $\mathrm{GnRH}$ receptor blocker (Dong et al., 2011). Although there is no direct evidence of such effects in humans, findings from other studies might be attributed to these cellular mechanisms; prolonged electrocardiographic QT intervals were recorded in GnRHa treated prostate cancer patients (Garnick et al., 2004), and GnRHa therapy in young women with symptomatic uterine leiomyoma, endometriosis, or candidates for in vitro fertilization led to significantly reduced peak flow velocity and cardiac index (stroke volume $\times$ heart rate; Eckstein et al., 1993).

A possibility of direct GnRHa effect on heart rhythm makes interpretation of the HRV results difficult, since HRV is only a proxy for central, prefrontally mediated inhibitory processes that are peripherally expressed through cardiac vagal influence (Thayer et al., 2012). At the planning stage of this study, the possibility of such interactions had not been described. If further confirmed, these findings can make applicability of HRV as a measure of emotional regulation capacity invalid in individuals receiving GnRHa treatment.

\section{Assessment of Emotional Processing-Conclusions and Further Steps}

Overall, our findings do not provide firm conclusions with regard to differences in emotional processing between the GnRHa treated CPP girls and age-matched controls. The diversity of the results suggests that more emphasis should be put on the investigation of emotion processing in future studies. In this respect both psychophysiological and experimental paradigms that tap in to the different domains of emotional processing and regulation (i.e., capacity, reactivity, recovery, and sensitivity) should be considered.

\section{Methodological Considerations}

Psychological functioning of GnRHa treated CPP girls may depend on a number of different mechanisms including direct effects of GnRHa on the brain, cessation of sex steroid influences, degree of exposure to the pubertal hormones before treatment initiation, the course of the CPP condition itself or psychosocial/educational environment. It is thus difficult to isolate the impact of GnRHa treatment on psychological functioning. The most appropriate study design to discriminate between GnRHa effects and other factors would be a randomized controlled trial (RCT). Since a RCT cannot be conducted due to ethical reasons, the most obvious alternatives include comparison of treated CPP children and controls matched for either chronological or biological age, in a cross-sectional or a longitudinal study. Comparison of cognitive development trajectories of non-CPP control and CPP-treatment groups through several measurement points, i.e., pre-, under- and post-treatment can provide most hints about GnRHa treatment impact on cognitive development. Nevertheless, while providing more information, the longitudinal design still cannot ensure proper isolation of GnRHa influence on brain development from the natural course of the condition, including pretreatment 
sex steroid exposure. Furthermore, the question remains if matching should be done by chronological or biological age. It can be argued that matching by chronological age is not appropriate since CPP children's biological age is higher than that of their chronological age peers. Matching by biological age would ensure comparable levels of biological maturation between the groups, which theoretically could increase the likelihood that the observed cognitive differences are indeed related to the actions of GnRHa. On the other hand, development of cognitive functioning cannot be separated from environmental influences. The majority of the GnRHa treated CPP girls attend school classes that are appropriate to their chronological age and socialize with the same age peers. It is therefore, in our opinion, more ecologically valid to evaluate cognitive functioning in comparison to the same chronological age population.

Finally, to gain mechanistic insights into the GnRHa effects on brain development, animal studies might provide further knowledge. Our group has previously conducted a twin sheep RCT where one of the twins had their puberty blocked with GnRHa. The results indicated that GnRHa might have influenced the development of cognitive functions related to emotion processing, while no clear effects on cognitive functions that did not involve emotional processing were found (Wojniusz et al., 2011, 2013; Evans et al., 2012; Nuruddin et al., 2013a,b,c; Robinson et al., 2014). While this study represented a delayed rather than precocious puberty model and translation of the results to humans should be made with caution, it suggests emotional processing as a potential area of GnRHa influence on the brain.

\section{Sample Size and Limitations}

Due to the low number of CPP patients receiving GnRHa treatment, only 15 CPP girls were included in this study, which can limit its statistical power. Nevertheless, post-hoc power analysis showed $1-\beta$ to be 0.75 , which gives a fair chance of rejecting the false null hypothesis taking into account a group difference of interest of $1 S D$. We argue that with regard to most of the cognitive tests and questionnaires used in this study, particularly those with known norm data, $1 S D$ represents a boundary of what is a clinically interesting difference. Although more participants would increase the statistical power and possibility of discovering smaller group differences, in our opinion, the present study provides useful information and suggestions for future research areas in a field that to date has been rarely investigated.

Regarding experimental and physiological measures for assessment of emotion processing, in the hindsight, we did not fully succeed in our choice of methods. While the results of EFT were ambiguous, perhaps depending on motivational factors, and overall difficult to interpret, the HRV findings were possibly not even valid as a proxy of cardiac vagal influence (see Section Cardiac Function and Emotional Regulation). Alternative approaches that could be applied in future studies could include functional neuro-imaging techniques to detect subtle changes of emotion processing directly within the central nervous system rather than applying peripheral proxies. Alternative behavioral measures of emotionrelated attentional processing could be obtained via more implicit approaches that are less confounded by motivational states (e.g., eye-tracking).

\section{Conclusion}

Overall, the findings suggest that GnRHa treated CPP girls do not differ in their cognitive functioning, behavioral, and social problems from the same age peers, at least, in settings that do not involve emotional processing. Although our findings with regard to emotional regulation and reactivity are inconclusive, they provide hints that CPP girls may differ in these areas from same age peers. We, therefore, suggest that future studies should to a higher degree emphasize investigation of emotional processing in a CPP population.

Finally, the differences in cardiac rhythm, expressed as lower HR in the CPP group and the fact that they were increasing with treatment duration, should be more closely followed up in the future, making use of methodologies that are appropriate for investigation of cardiac health.

\section{AUTHOR CONTRIBUTIONS}

SW, One of the designers of the study; collected the data with regard to CANTAB, HRV, and EFT tests; analyzed the data from these experiments and drafted the manuscript with regard to introductory part, methods and analysis of CANTAB, HRV, and EFT, and drafted the discussion. NC, One of the designers of the study; main responsibility for subject recruitment; collected and analyzed the data with regard to neuropsychological tests and behavioral questionnaires; drafted the parts of the article associated with neuropsychological tests and behavioral questionnaires. SS, Took part in the data analysis and interpretation of results with regard to HRV and EFT experiments; critically reviewed the data analysis and the manuscript. SA, Responsible for the design of neuropsychological test battery; critically reviewed the data analysis and the manuscript. JD, IG, JV, KD, SV, MCr, Participated in subject recruitment/treatment; critically reviewed the data analysis and the manuscript. CV, Participated in design of the study; critically reviewed the data analysis and the manuscript. MCo, One of the designers of the study; participated in subject assessment/recruitment/treatment; critically reviewed the data analysis and the manuscript. $\mathrm{IH}$, Primary investigator; responsible for the design of the study; critically reviewed the data analysis, and the manuscript.

\section{FUNDING}

The study has been funded by the Department of Medical Neurobiology, Oslo University Hospital, Norway. 


\section{REFERENCES}

(1996). Heart rate variability. Standards of measurement, physiological interpretation, and clinical use. Task Force of the European Society of Cardiology and the North American Society of Pacing and Electrophysiology. Eur. Heart J. 17, 354-381.

Appelhans, B. M., and Luecken, L. J. (2006). Heart rate variability as an index of regulated emotional responding. Rev. Gen. Psych. 10, 229-240. doi: 10.1037/1089-2680.10.3.229

Atkinson, L., and Yoshida, G. (1989). A basic programme for determining reliability and validity of subtest combination short forms. Educ. Psychol. Meas. 49, 141-143. doi: 10.1177/0013164489491013

Biro, F. M., Greenspan, L. C., Galvez, M. P., Pinney, S. M., Teitelbaum, S., Windham, G. C., et al. (2013). Onset of breast development in a longitudinal cohort. Pediatrics 132, 1019-1027. doi: 10.1542/peds.2012-3773

Bishop, S., Duncan, J., Brett, M., and Lawrence, A. D. (2004). Prefrontal cortical function and anxiety: controlling attention to threat-related stimuli. Nat. Neurosci. 7, 184-188. doi: 10.1038/nn1173

Carel, J. C., Eugster, E. A., Rogol, A., Ghizzoni, L., Palmert, M. R., Antoniazzi, F., et al. (2009). Consensus statement on the use of gonadotropinreleasing hormone analogs in children. Pediatrics 123, e752-e762. doi: 10.1542/peds.2008-1783

Chen, M., and Eugster, E. A. (2015). Central Precocious Puberty: update on diagnosis and treatment. Paediatr. Drugs 17, 273-281. doi: 10.1007/s40272-0150130-8

Choi, K. H., Chung, S. J., Kang, M. J., Yoon, J. Y., Lee, J. E., Lee, Y. A., et al. (2013). Boys with precocious or early puberty: incidence of pathological brain magnetic resonance imaging findings and factors related to newly developed brain lesions. Ann. Pediatr. Endocrinol. Metab. 18, 183-190. doi: 10.6065/apem.2013.18.4.183

Cohen, J. (1992). A power primer. Psychol. Bull. 112, 155-159. doi: 10.1037/00332909.112.1.155

Craig, M. C., Fletcher, P. C., Daly, E. M., Rymer, J., Cutter, W. J., Brammer, M., et al. (2007). Gonadotropin hormone releasing hormone agonists alter prefrontal function during verbal encoding in young women. Psychoneuroendocrinology 32, 1116-1127. doi: 10.1016/j.psyneuen.2007.09.009

de Houwer, J., and Tibboel, H. (2010). Stop what you are not doing! Emotional pictures interfere with the task not to respond. Psychon. Bull. Rev. 17, 699-703. doi: 10.3758/PBR.17.5.699

Delis, D. C., Kaplan, E., and Kramer, J. H. (2001). Delis Kaplan Executive Function System Examiner's Manual. San Antonio, TX: The Psychological Corporation.

Dong, F., Skinner, D. C., Wu, T. J., and Ren, J. (2011). The heart: a novel gonadotrophin-releasing hormone target. J. Neuroendocrinol. 23, 456-463. doi: 10.1111/j.1365-2826.2011.02119.x

Eckstein, N., Pines, A., Fisman, E. Z., Fisch, B., Limor, R., Vagman, I., et al. (1993). The effect of the hypoestrogenic state, induced by gonadotropinreleasing hormone agonist, on Doppler-derived parameters of aortic flow. J. Clin. Endocrinol. Metab. 77, 910-912.

Ehrhardt, A. A., and Meyer-Bahlburg, H. F. (1986). Idiopathic precocious puberty in girls: long-term effects on adolescent behavior. Acta Endocrinol. Suppl. (Copenh). 279, 247-253. doi: 10.1530/acta.0.112s247

Evans, N. P., Robinson, J. E., Erhard, H. W., Ropstad, E., Fleming, L. M., and Haraldsen, I. R. (2012). Development of psychophysiological motoric reactivity is influenced by peripubertal pharmacological inhibition of gonadotropin releasing hormone action-results of an ovine model. Psychoneuroendocrinology 37, 1876-1884. doi: 10.1016/j.psyneuen.2012.03.020

Faul, F., Erdfelder, E., Lang, A. G., and Buchner, A. (2007). G*Power 3: a flexible statistical power analysis program for the social, behavioral, and biomedical sciences. Behav. Res. Methods 39, 175-191. doi: 10.3758/BF03193146

Galatzer, A., Beth-Halachmi, N., Kauli, R., and Laron, Z. (1984). Intellectual Function of Girls with Precocious Puberty. Pediatrics 74, 246-249.

Garnick, M. B., Pratt, C. M., Campion, M., and Shipley, J. (2004). The effect of hormonal therapy for prostate cancer on the electrocardiographic QT interval: phase 3 results following treatment with leuprolide and goserelin, alone or with bicalutamide, and the GnRH antagonist abarelix. J. Clin. Oncol. 22, 4578. Available online at: http://meeting.ascopubs.org/cgi/content/abstract/22/ 14_suppl/4578
Grigorova, M., Sherwin, B. B., and Tulandi, T. (2006). Effects of treatment with leuprolide acetate depot on working memory and executive functions in young premenopausal women. Psychoneuroendocrinology 31, 935-947. doi: 10.1016/j.psyneuen.2006.05.004

Grose-Fifer, J., Rodrigues, A., Hoover, S., and Zottoli, T. (2013). Attentional capture by emotional faces in adolescence. Adv. Cogn. Psychol. 9, 81-91. doi: 10.5709/acp-0134-9

Herbert, C., and Sütterlin, S. (2011). Response inhibition and memory retrieval of emotional target words: evidence from an emotional stop-signal task. J. Behav. Brain Sci. 1, 153-159. doi: 10.4236/jbbs.2011.13020

Hugdahl, K., Thomsen, T., and Ersland, L. (2006). Sex differences in visuo-spatial processing: an fMRI study of mental rotation. Neuropsychologia 44, 1575-1583. doi: 10.1016/j.neuropsychologia.2006.01.026

ILO (1990). International Standard Classification of Occupations: ISCO-88. Geneva: ILO.

Johansson, T., and Ritzen, E. M. (2005). Very long-term follow-up of girls with early and late menarche. Endocr. Dev. 8, 126-136. doi: 10.1159/000084098

Kakar, S. S., and Jennes, L. (1995). Expression of gonadotropin-releasing hormone and gonadotropin-releasing hormone receptor mRNAs in various non-reproductive human tissues. Cancer Lett. 98, 57-62. doi: 10.1016/S03043835(06)80010-8

Kaufmann, T., Sutterlin, S., Schulz, S. M., and Vogele, C. (2011). ARTiiFACT: a tool for heart rate artifact processing and heart rate variability analysis. Behav. Res. Methods 43, 1161-1170. doi: 10.3758/s13428-011-0107-7

Keating, N. L., O’Malley, A. J., Freedland, S. J., and Smith, M. R. (2010). Diabetes and cardiovascular disease during androgen deprivation therapy: observational study of veterans with prostate cancer. J. Natl. Cancer Inst. 102, 39-46. doi: 10.1093/jnci/djp404

Kim, E. Y., and Lee, M. I. (2012). Psychosocial aspects in girls with idiopathic precocious puberty. Psychiatry Investig. 9, 25-28. doi: 10.4306/pi.2012.9.1.25

Koval, P., Ogrinz, B., Kuppens, P., Van den Bergh, O., Tuerlinckx, F., and Sutterlin, S. (2013). Affective instability in daily life is predicted by resting heart rate variability. PLoS ONE 8:e81536. doi: 10.1371/journal.pone.0081536

Levens, S. M., and Phelps, E. A. (2008). Emotion processing effects on interference resolution in working memory. Emotion 8, 267-280. doi: 10.1037/15283542.8.2.267

Luciana, M., and Nelson, C. A. (2002). Assessment of neuropsychological function through use of the Cambridge Neuropsychological Testing Automated Battery: performance in 4- to 12-year-old children. Dev. Neuropsychol. 22, 595-624. doi: 10.1207/S15326942DN2203_3

Lundqvist, D., Flykt, A., and Öhman, A. (1998). The Karolinska Directed Emotional Faces - KDEF. CD ROM from Department of Clinical Neuroscience, Psychology section, Karolinska Institutet.

Mueller, S. C., Merke, D. P., Leschek, E. W., Fromm, S., Grillon, C., Cornwell, B. R., et al. (2011). Grey matter volume correlates with virtual water maze task performance in boys with androgen excess. Neuroscience 197, 225-232. doi: 10.1016/j.neuroscience.2011.09.022

Nebesio, T. D., and Eugster, E. A. (2007). Current concepts in normal and abnormal puberty. Curr. Probl. Pediatr. Adolesc. Health Care 37, 50-72. doi: 10.1016/j.cppeds.2006.10.005

Nuruddin, S., Bruchhage, M., Ropstad, E., Krogenaes, A., Evans, N. P., Robinson, J. E., et al. (2013a). Effects of peripubertal gonadotropin-releasing hormone agonist on brain development in sheep-A magnetic resonance imaging study. Psychoneuroendocrinology 38, 1994-2002. doi: 10.1016/j.psyneuen.2013.03.009

Nuruddin, S., Krogenaes, A., Brynildsrud, O. B., Verhaegen, S., Evans, N. P., Robinson, J. E., et al. (2013b). Peri-pubertal gonadotropin-releasing hormone agonist treatment affects sex biased gene expression of amygdala in sheep. Psychoneuroendocrinology 38, 3115-3127. doi: 10.1016/j.psyneuen.2013. 09.011

Nuruddin, S., Wojniusz, S., Ropstad, E., Krogenaes, A., Evans, N. P., Robinson, J. E., et al. (2013c). Peri-pubertal gonadotropin-releasing hormone analog treatment affects hippocampus gene expression without changing spatial orientation in young sheep. Behav. Brain Res. 242, 9-16. doi: 10.1016/j.bbr.2012.12.027

Robinson, J. E., Evans, N. P., Dumbell, R., Solbakk, A. K., Ropstad, E., and Haraldsen, I. R. (2014). Effects of inhibition of gonadotropin releasing hormone secretion on the response to novel objects in young male and female 
sheep. Psychoneuroendocrinology 40, 130-139. doi: 10.1016/j.psyneuen.2013. 11.005

Saan, R. J., and Deelman, B. G. (1986). De 15-Woordentests A en B. Een Voorlopige Handleiding (Intern Rapport). Groningen: AZG, afd. Neuropsychologie.

Shepard, R. N., and Metzler, J. (1971). Mental rotation of three-dimensional objects. Science 171, 701-703. doi: 10.1126/science.171.3972.701

Skinner, D. C., Albertson, A. J., Navratil, A., Smith, A., Mignot, M., Talbott, H., et al. (2009). Effects of gonadotrophin-releasing hormone outside the hypothalamic-pituitary-reproductive axis. J. Neuroendocrinol. 21, 282-292. doi: 10.1111/j.1365-2826.2009.01842.x

Smidts, D., and Huizinga, M. (2009). BRIEF: Executieve Functies Gedragsvragenlijst. Amsterdam: Hogrefe Uitgevers.

Sonis, W. A., Comite, F., Blue, J., Pescovitz, O. H., Rahn, C. W., Hench, K. D., et al. (1985). Behavior problems and social competence in girls with true precocious puberty. J. Pediatr. 106, 156-160. doi: 10.1016/S0022-3476(85)80489-3

Teilmann, G., Pedersen, C. B., Jensen, T. K., Skakkebaek, N. E., and Juul, A. (2005). Prevalence and incidence of precocious pubertal development in Denmark: an epidemiologic study based on national registries. Pediatrics 116, 1323-1328. doi: $10.1542 /$ peds.2005-0012

Thayer, J. F., Ahs, F., Fredrikson, M., Sollers, J. J. III, and Wager, T. D. (2012). A meta-analysis of heart rate variability and neuroimaging studies: implications for heart rate variability as a marker of stress and health. Neurosci. Biobehav. Rev. 36, 747-756. doi: 10.1016/j.neubiorev.2011.11.009

Thayer, J. F., and Lane, R. D. (2009). Claude Bernard and the heart-brain connection: further elaboration of a model of neurovisceral integration. Neurosci. Biobehav. Rev. 33, 81-88. doi: 10.1016/j.neubiorev.2008. 08.004

Trahan, D. E., and Larrabee, G. J. (1988). Professional Manual: Continuous Visual Memory Test. Odessa, FL: Psychological Assessment Resources.

Tremblay, L., and Frigon, J. Y. (2005). Precocious puberty in adolescent girls: a biomarker of later psychosocial adjustment problems. Child Psychiatry Hum. Dev. 36, 73-94. doi: 10.1007/s10578-004-3489-2

Tsai, H. K., D’Amico, A. V., Sadetsky, N., Chen, M. H., and Carroll, P. R. (2007). Androgen deprivation therapy for localized prostate cancer and the risk of cardiovascular mortality. J. Natl. Cancer Inst. 99, 1516-1524. doi: 10.1093/jnci/djm 168

Verhulst, F. C., and Van der Ende, J. (2004). Handleiding Voor de CBCL. Rotterdam: Erasmus MC, Sophia Kinderziekenhuis, afd. Kinder- en Jeugdpsychiatrie.

Wojniusz, S., Ropstad, E., Evans, N., Robinson, J., Solbakk, A. K., Endestad, T., et al. (2013). Sex-specific development of spatial orientation is independent of peripubertal gonadal steroids. Psychoneuroendocrinology 38, 1709-1716. doi: 10.1016/j.psyneuen.2013.02.005

Wojniusz, S., Vogele, C., Ropstad, E., Evans, N., Robinson, J., Sutterlin, S., et al. (2011). Prepubertal gonadotropin-releasing hormone analog leads to exaggerated behavioral and emotional sex differences in sheep. Horm. Behav. 59, 22-27. doi: 10.1016/j.yhbeh.2010.09.010

Xhrouet-Heinrichs, D., Lagrou, K., Heinrichs, C., Craen, M., Dooms, L., Malvaux, P., et al. (1997). Longitudinal study of behavioral and affective patterns in girls with central precocious puberty during long-acting triptorelin therapy. Acta Paediatr. 86, 808-815. doi: 10.1111/j.1651-2227.1997.tb08602.x

Conflict of Interest Statement: The authors declare that the research was conducted in the absence of any commercial or financial relationships that could be construed as a potential conflict of interest.

The reviewer, MK, and handling Editor declared their shared affiliation, and the handling Editor states that the process nevertheless met the standards of a fair and objective review.

Copyright (C) 2016 Wojniusz, Callens, Sütterlin, Andersson, De Schepper, Gies, Vanbesien, De Waele, Van Aken, Craen, Vögele, Cools and Haraldsen. This is an open-access article distributed under the terms of the Creative Commons Attribution License (CC BY). The use, distribution or reproduction in other forums is permitted, provided the original author(s) or licensor are credited and that the original publication in this journal is cited, in accordance with accepted academic practice. No use, distribution or reproduction is permitted which does not comply with these terms. 